\title{
Smoking and Ischemic Heart Disease Disparities Between Studies, Genders, Times, and Socioeconomic Strata
}

\author{
Bruce N. Leistikow
}

Received: 26 March 2009/Accepted: 22 May 2009/Published online: 30 June 2009

(C) The Author(s) 2009. This article is published with open access at Springerlink.com

\begin{abstract}
Large, unexplained, but possibly related disparities exist between heart disease risks observed in differing genders, educational levels, times, and studies. Such heart disease disparities might be related to cumulative tobacco smoke damage (smoke load) disparities that are overlooked in standard assessments of point smoking status. So, I reviewed possible relationships between smoke load and heart disease levels across genders, educational strata, years, and leading studies. Smoker heart disease risk assessments in the Nurses Health Study (Nurses), Cancer Prevention Study-II (CPS-II), and British Doctors studies were compared and related to their likely selection and misclassification biases. Relationships between smoke loads and United States (US) education- and genderrelated heart disease mortality disparities were qualitatively assessed using lung cancer rates as a smoke load proxy. The high heart disease mortality risks observed in smoking Nurses in 1980-2004 and in less educated US women in 2001 were qualitatively associated with their higher smoke loads and lower selection and exposure misclassification biases than in the CPS-II and Doctors studies. Smokingattributable heart disease death tolls and disparities extrapolated from mortality ratios from the CPS-II and Doctors studies may be substantial underestimates. Such studies appear to have compared convenience samples of light smokers to lighter smokers instead of comparing representative smokers to the unexposed. Further efforts to minimize smoke exposures and better quantify cumulative smoking-attributable burdens are needed.
\end{abstract}

B. N. Leistikow $(\bowtie)$

Department of Public Health Sciences, University of California, Davis,

1 Shields Avenue,

Davis, CA 95616, USA

e-mail: BNLeistikow@ucdavis.edu
Keywords Smoking · Ischemic Heart Disease · Mortality · Socioeconomic Status · Gender · Disparities

\section{Introduction}

Large, deadly, unexplained, but possibly related disparities exist between heart disease risks observed in less versus more educated groups, 1993 versus 2001, women versus men [14], and different studies and definitions of "smoking" $[18,33]$. Thus, while at age $25-64$ years, female heart disease age-standardized mortality rates per 100,000 (rates) fell in most groups, they inexplicably rose in the lowest education ( $<12$ years) US White women from 84 in 1993 to 98 per 100,000 in 2001 [14]. That 2001 rate was twice the United States (US) male and six times the White female heart disease mortality rates seen in the most educated (16+ years of education) in 2001 [14]. Also, unexplained are disparities between the female smoker age-adjusted ischemic heart disease (IHD) mortality ratios of 3.3 (95\% confidence interval (CI) 2.9-3.8) in Nurses Health Study (Nurse) smokers versus 1.6 (CI 1.4-1.7) in the Cancer Prevention Study-II (CPS-II) from which official US and global smoking-attributable heart disease mortality estimates are extrapolated [18, 33]. Lastly, relationships between smoking and US male/female mortality rate disparities in 2001 that were reversed for lung cancer and trending toward reversal for heart disease in the highly educated are unexplained [14].

Given the large unexplained decreases in genderrelated and increases in education or smoking-related heart disease mortality disparities noted above, a closer review of the possible sources of such disparities seems merited. So, I overviewed possible oversights in past assessments of relationships of smoking to heart disease 
mortality disparities between genders, socioeconomic strata, times, and major cohorts.

\section{Methods}

I contrasted methods and their relationships to IHD mortality ratios in four leading cohort studies. The studies selected were: (1) the Nurses Health Study (NHS) 19802004 follow-up due to its recency, methodologic strengths, and high mortality ratios in smokers; (2) CPS-II [33] since it has been extrapolated into recent estimates of 443,000 annual US [1] and up to one billion global twenty-first century smoking-attributable deaths [37]; and the British (3) male and (4) female Doctors Studies, since they seem to be earlier, smaller, British versions of the methods in CPSII [9-11, 33].

The NHS began with about 122,000 healthy, married US female nurses ages 30 to 55 years from 11 states in 1976 [18], though only the 1980-2004 data were used in the recent analyses I discuss (Tables 1 and 2). The NHS is relatively unique among large cohort studies in recency, use of biennial exposure reassessment, juried cause of death assignment, and fixing of smoking status for analysis purposes at the biennial assessment prior to the diagnosis of vascular, neoplastic, or respiratory disease. Those methods help to minimize exposure and outcome (detection) misclassification biases and confounding by nonfatal diseases, respectively [18].

The CPS-II is the very large US cohort on which most US and global smoking-attributable mortality estimates are based. It began in 1982 with about 480,000 women ages $45+$ years in cancer society member acquaintance households [33]. The CPS-II cohort both used a definition of "never smoker" that misclassifies smokers as "never smokers"[7] and has subsequently been shown to have disproportionately high education, life expectancy, and probable smoking cessation rates and thus probably low smoke exposures relative to the US population [31, 32].

The British male and female Doctors Studies are the longest (1951-2001 and 1951-1972, respectively) early large cohort studies of smoking effects. Since true "nonsmokers" were thought to be nonexistent at the time, less regular smokers (those denying smoking at least one cigarette daily for 365 days consecutively) were termed never smokers at least near the initiation of the study in $1951[7,8]$.

Possible selection and misclassification biases in the CPS-II, NHS, and Doctors studies were evaluated by reviewing their methods including timing, enrollment criteria, exclusions, smoking prevalence, age, "never" and "current" smoker definitions, and means of cause of death

Table 1 Background information on the Nurses, CPS-II, and British Doctors studies

\begin{tabular}{|c|c|c|c|c|}
\hline & \multicolumn{4}{|l|}{ Study } \\
\hline & Nurses Health [18] & $\begin{array}{l}\text { Cancer Prevention Study-II } \\
\text { (CPS-II) [33] }\end{array}$ & British Doctors Males [10] & $\begin{array}{l}\text { British Doctors Females } \\
\text { [9] }\end{array}$ \\
\hline $\begin{array}{l}\text { Analytic cohort } \\
\text { nos. }\end{array}$ & About 100,000 & 711,000 , about $2 / 3$ women & $\begin{array}{l}34,440 \text {, about } 2 / 3 \text { of } \\
\text { eligible male doctors }\end{array}$ & 6,194 \\
\hline Enrollment & $\begin{array}{l}\text { 1976, but Kenfield excluded } \\
1976-1980 \text { data }\end{array}$ & Fall, 1982 & 1951 & 1951 \\
\hline $\begin{array}{l}\text { End of follow- } \\
\text { up }\end{array}$ & $\begin{array}{l}2004 \text { for Kenfield hazard } \\
\text { ratios [18]; 2002/2003 for } \\
\text { mortality rates [28] }\end{array}$ & $12 / 31 / 1988$ & 2001 & 1972 \\
\hline $\begin{array}{l}\text { Enrollment } \\
\text { criteria }\end{array}$ & $\begin{array}{l}\text { Initially healthy, female } \\
\text { married registered nurses } \\
\text { from } 11 \text { states }\end{array}$ & $\begin{array}{l}\text { Friends, neighbors, and } \\
\text { acquaintances of American } \\
\text { Cancer Society volunteers }\end{array}$ & British male physicians & $\begin{array}{l}\text { British female } \\
\text { physicians }\end{array}$ \\
\hline Exclusions & $\begin{array}{l}\text { 1976-1980 data and the } \\
\text { unmarried, or diseased [18] }\end{array}$ & $\begin{array}{l}\text { Pipe, cigar, or unclassifiable } \\
\text { smokers }\end{array}$ & $\begin{array}{l}\text { Users of any tobacco } \\
\text { except cigarettes }\end{array}$ & $\begin{array}{l}\text { Users of any tobacco } \\
\text { except cigarettes }\end{array}$ \\
\hline $\begin{array}{l}\text { Initial current/ } \\
\text { ever smoking } \\
\text { prevalence }\end{array}$ & $28 \% / 54.3 \%$ & $\begin{array}{l}\text { Age adjusted in White women, } \\
20 \% / 42 \%\end{array}$ & $\sim 80 \% / 83 \%$ & $-/ 50 \%$ \\
\hline $\begin{array}{l}\text { Exposure } \\
\text { reassessment }\end{array}$ & $\begin{array}{l}\text { Biennial until disease } \\
\text { diagnosed [18] }\end{array}$ & None in the 6 years analyzed & Every 6-13 years & Every 6-9 years \\
\hline $\begin{array}{l}\text { Outcome } \\
\text { assessment }\end{array}$ & $\begin{array}{l}\text { Juried by experts with terminal } \\
\text { care records for } 94 \% \text { of deaths }\end{array}$ & Death certificate & $\begin{array}{l}\text { Death certificate unless } \\
\text { lung cancer }\end{array}$ & $\begin{array}{l}\text { Death certificate unless } \\
\text { lung cancer }\end{array}$ \\
\hline Ages analyzed & 34-84 years & $35+$ years & $\sim 20+$ years & $\sim 20+$ years \\
\hline URL/link & $\begin{array}{l}\text { http://jama.ama-assn.org/cgi/ } \\
\text { content/short/299/17/2037 }\end{array}$ & $\begin{array}{l}\text { http://cancercontrol.cancer.gov/ } \\
\text { TCRB/monographs/8/index. } \\
\text { html }\end{array}$ & $\begin{array}{l}\text { http://www.bmj.com/cgi/ } \\
\text { content/abstract/ } \\
\text { bmj.38142.554479.AEv1 }\end{array}$ & $\begin{array}{l}\text { http://www.ncbi.nlm.nih. } \\
\text { gov/pubmed/7417764? } \\
\text { dopt=Citation }\end{array}$ \\
\hline
\end{tabular}




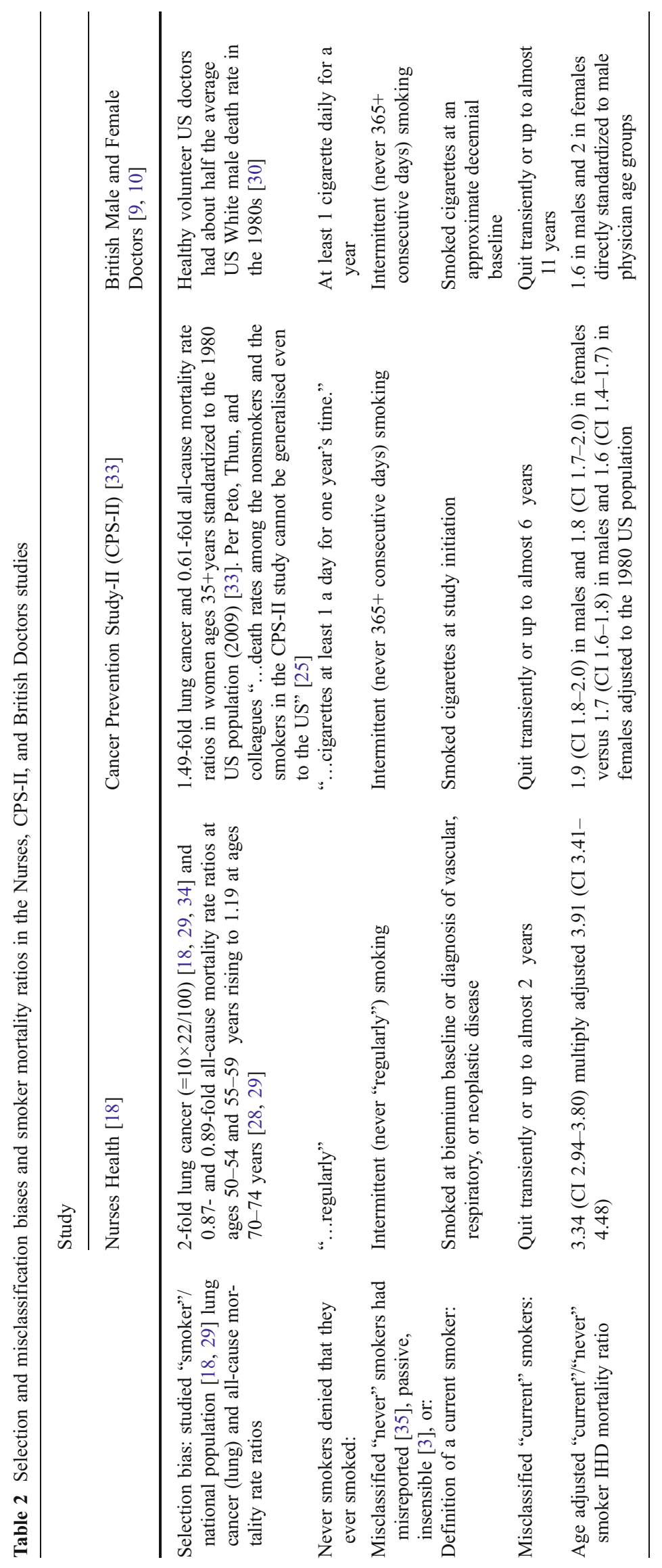


assignment (Table 1) and biases and/or mortality rate ratios versus the general population (Table 2). Table 2 helps to quantify selection bias possibly due to the disproportionate selection of light "smokers" by comparing lung cancer or all cause mortality rates in the cohort or similar groups to the general population. One would expect representative smokers to have far higher mortality rates than average Americans, about $3 / 4$ of whom deny current smoking. Table 2 helps to overview exposure misclassification bias by comparing definitions of "smoking" in the cohort to the types of smoke exposure overlooked by each definition of "smoker." Given the selection and exposure misclassification biases in those studies (Tables 1 and 2), other more representative exposure/outcome associations seem to be needed. So, I qualitatively contrasted 1993 and 2001 US female heart disease and lung cancer mortality rates and smoking prevalence across educational strata $[2,14]$ since such mortality rates were more current and widely used than other (income, class, deprivation, ...) socioeconomic stratifications in the USA, lung cancer rates are a good proxy for cumulative tobacco smoke damage (smoke load) $[19-22,26]$, and US data had been used in the Nurses and CPS-II analyses [18, 33].

\section{Results}

The studies reviewed addressed distinct populations, times, and other background differences (Table 1); definitions of "never" and "current" smoking with attendant differences in exposure misclassification (Table 2); and smoker IHD mortality ratios (Table 2). Still, each study exhibited selection bias with narrow, skewed eligibility criteria (Table 1), low participant fractions
$(<3 \%)$, and/or low mortality rates, compared to the general population (Table 2). Selection bias was substantial in Nurses. Nurse "smokers" had little (1.19-fold at ages 70$74)$ to no (0.87-fold at ages 50-54) more premature mortality than nationally representative women yet thrice the all-cause mortality rate of Nurse never smokers (Table 2) $[18,28]$. Selection bias was even clearer and stronger in CPS-II women age 35+years, where "never" and "current" smokers had lung cancer death rates $87 \%$ and $-49 \%$, respectively, and all-cause death rates $65 \%$ and $39 \%$, respectively, below all US female averages for the 1983-1988 period [29, 33]. Prominent epidemiologists Peto, Thun, and Lopez wrote this about CPS-II: “...death rates among the nonsmokers and the smokers in the CPSII study cannot be generalised even to the US, let alone to other populations. For example, the probability that a 35 year-old man will die before 70 is $34 \%$ at US 1985 death rates, but only $13 \%$ and $32 \%$ at the non-smoker and smoker death rates in years 3-6 of CPS-II." [25].

Heart disease and lung cancer mortality rates by education stratum and year in White US women at working ages are shown in Fig. 1. The data are for decedents from 43 states who were age 25-64 years with recorded years of education [14]. Smoke load (lung cancer rate in red and graphed on the $y-1$ axis) and heart disease rate levels (graphed on the right $(y-2)$ axis) generally were closely proportional to each other across education and time strata and both rose proportionately in the least educated, were stable in high school graduates, and fell in the most educated (Fig. 1).

Figure 2 contrasts male and female smoke loads, as reflected in lung cancer rates, by the same year-education strata as in Fig. 1. Smoke load changes from 1993 to 2001 ranged from a $22 \%$ increase in the least educated women to $1 \%, 17 \%$, and $34 \%$ decreases in the least educated men and
Fig. 1 United States White female lung cancer and heart disease mortality rates by year and years of education, ages 25-64 years

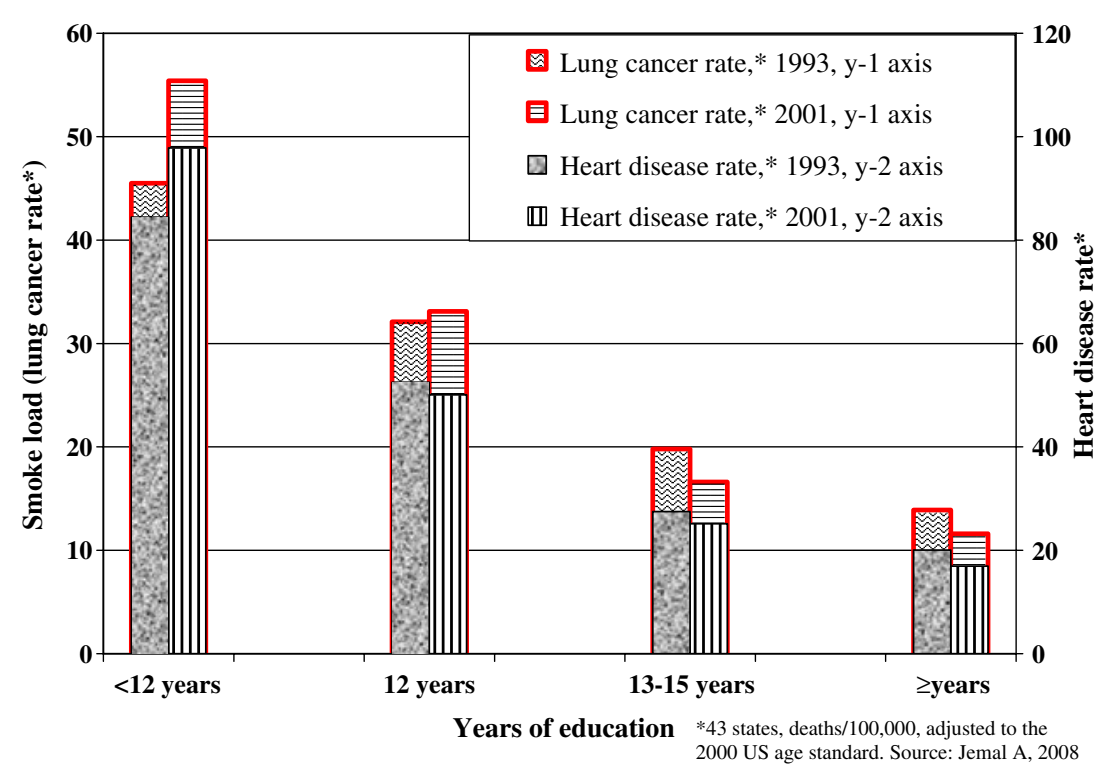


Fig. 2 United States White lung cancer mortality rates by gender-year-years of education, ages $25-64$ years

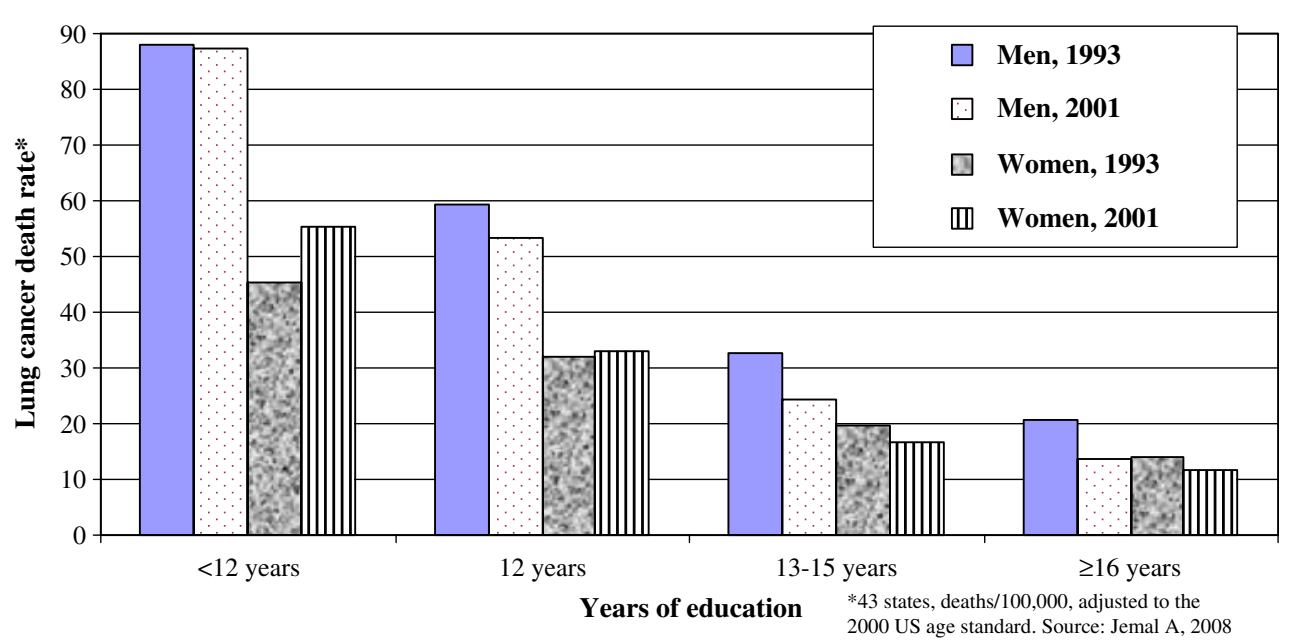

all occurred in the most educated men (Figs. 2 and 3), a group overrepresented in CPS-II [33]. As expected, reduced selection and misclassification biases in Nurses appear to have resulted in greater disparities between Nurse than CPS-II female "current" versus "never" smoker exposures and death rates. That is suggested by Nurse "smoker" mortality ratios that are higher than in CPS-II women for lung cancer or all-causes versus national averages (Table 2) or for all-causes versus "never" smokers (age-adjusted allcause mortality ratios of 2.77 (CI 2.65-2.90) in Nurses versus 1.9 (CI 1.9-2.0) in CPS-II women). In other words, the improved definitions of "smoker" and more representative "smokers" in Nurses are associated with about 4-fold higher "smoker" IHD mortality excesses (2.3 (age adjusted) to 2.9 (multiply adjusted) in Nurses versus 0.6 to 0.8 in CPS-II women where excess risk equals IHD mortality ratios from Table 2, minus 1, the risk in the unexposed).

This study has several strengths. First, suggestions of higher smoking-related heart disease mortality burdens with
Fig. 3 United States White heart disease mortality rates by gender-year-years of education, ages $25-64$ years

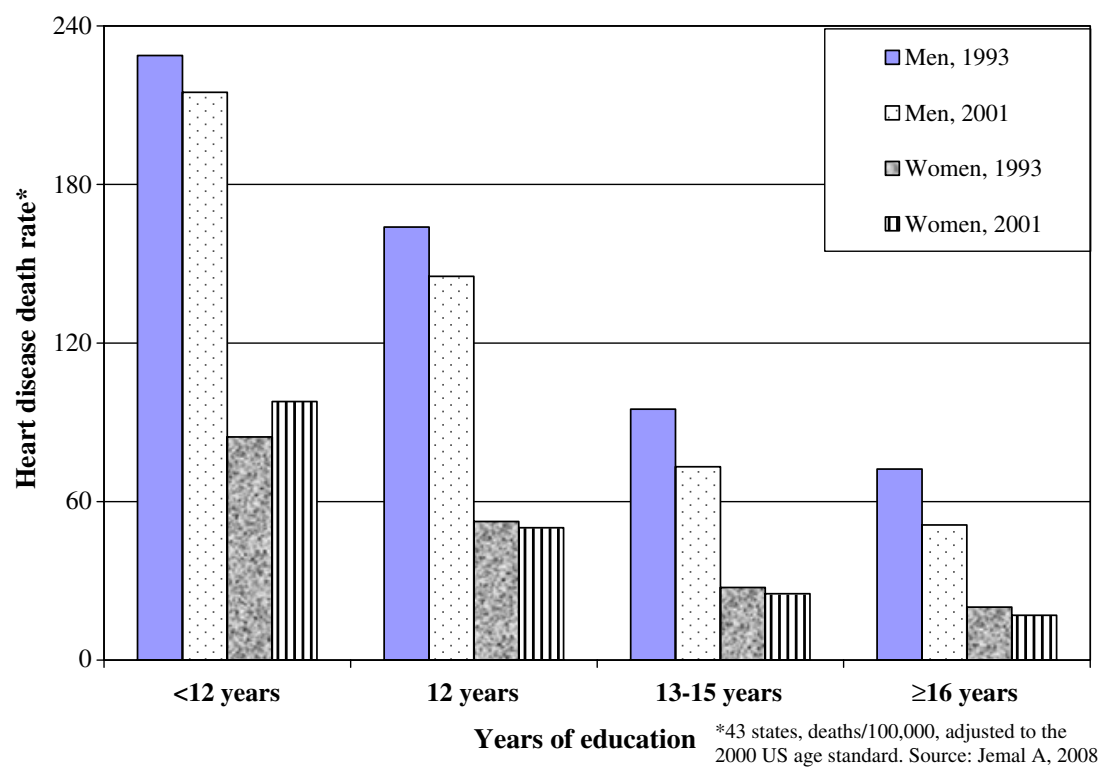


the higher quality cohort study methods in Nurses [18] corroborate the seemingly strong relationship between female smoke load and heart disease mortality rates across educational disparities (Fig. 1). Second, the general population lung cancer/heart disease rate associations (Fig. 1) qualitatively support suggestions that improved measurement of smoking will help account for more mortality disparities. Lung cancer rates are preferred as smoke load measures since they integrate several important aspects of exposure existence, duration, and level that are overlooked by selfreported point smoking status. For example, mortality is strongly related to forgotten [35], secondhand, insensible [3], and durational [27] aspects of exposure that are ignored in assessments of self-reported current active smoking. Second, the 1980-2004 Nurse [18] and 2001 national information studied is far more recent and less prone to selection, misclassification, and detection biases than are the 19821988 CPS-II and 1951-1972 female doctors data [35].

This review has weaknesses. Only three of the most prominent studies were discussed in depth, and all of them had some selection bias (Table 2). Despite their reduced misclassification bias compared to CPS-II, Nurses still had probably significant misclassification biases from secondhand and insensible smoking [3] and possibly from forgetfulness [35], never "regularly" smoking, or cessation periods between biennial reports of active smoking. Besides smoke load, other exposures could have differed between the studies. However, adjustment for numerous self-reported IHD risk factors raised the Nurse "smoker" IHD mortality hazard ratio from 3.34 to 3.91, widening the disparity between Nurse versus female CPS-II or Doctor mortality ratios [18]. The qualitative lung cancer/IHD mortality rate association across education levels (Fig. 1) exclude about seven states, are ecologic, and are based on proxy-reported decedent education levels and intercensal persons-at-risk estimates [14]. Lastly, little mention was made of the importance of smoking-related female lung cancer and other non-heart disease deaths. Yet, lung cancer alone killed nearly twice as many US women as breast cancer in 2005 [29], was increasingly disparate across education strata (Fig. 2), and appears to be persisting more in educated women than men (Fig. 2). Also, the Kenfield reanalysis of Nurses data linked smoking to both considerably greater mortality ratios and ranges of diseases than are included in official smoking-attributable mortality estimates [18].

Both this and several prior studies imply that heart disease mortality rate disparities might be largely linked to smoke load disparities and official estimates of death tolls from smoking may deserve to be raised substantially. A similar prior review of differing lung cancer risks found the differences to be largely due to differing smoke exposures [35]. Previous underestimation of strong relationships between smoking and heart disease mortality disparities are suggested by (1) the heightened IHD risk estimates in
Nurses when exposure misclassification and selection biases were reduced (Table 2), (2) persistent selection and misclassification biases in the Nurses study albeit smaller biases than in CPS-II, (3) close proportionality between the female smoke load and heart disease mortality levels over time and education in Fig. 1, and (4) prior papers. Jousilahti noted both that nonparticipants in a high (84\%) participation rate survey had twice the tobacco-related disease mortality rate of participants [17] and that smoker mortality relative risks fell considerably with even two added years of cessation-related misclassification of "current" smoking [16]. Taylor and Thun showed substantial effects of possible CPS-II misclassification of ex-smoking years as "smoking" years [32]. Wacholder et al. [36] Boffetta et al. [4] and Marshall et al. $[23,24]$ each have noted that study risk estimates are very sensitive to misclassification of exposure as occurred even in Nurses (Table 2) [3]. Recent papers by Jha et al. [15] and Gruer et al. [12] have suggested apparent dominant roles of smoking in socioeconomic mortality disparities.

This study has several implications. First, reducing active, secondhand, and insensible [3] smoking in all and especially the less educated (Fig. 2) and reducing bias in studies assessing or adjusting for smoking effects seem merited [23, $24,36]$. Second, as others have noted, development and use of better smoke load biochemical markers or sentinel health event smoke load bio-indices like lung cancer rates with juried cause of death assessments may be useful [13]. Third, increasing the numbers of studies which publish the absolute smoke loads and heart disease mortality rates in their exposed and control populations might allow both construction of smoke load/heart disease mortality rate dose-response curves across studies and assessment of which parts of that curve were best represented in individual cohorts.

Further research is needed to help better quantify and communicate smoke load risks to women and men. Communicating with women may be especially pressing since smoking prevalence, smoke loads, and/or heart disease mortality rates were falling faster in men of working age, thus rapidly trending toward female lung cancer and heart disease death rates exceeding men in the most educated, some northern states [6] and some northern European nations [37].

Open Access This article is distributed under the terms of the Creative Commons Attribution Noncommercial License which permits any noncommercial use, distribution, and reproduction in any medium, provided the original author(s) and source are credited.

\section{References}

1. Adhikari, B., Kahende, J., Malarcher, A., Pechacek, T., \& Tong, V. (2008). Smoking-attributable mortality, years of potential life lost, and productivity losses - United States, 2000-2004. MMWR Morbidity and Mortality Weekly Report, 57, 1226-1228. 
2. Albano, J. D., Ward, E., Jemal, A., Anderson, R., Cokkinides, V. E., Murray, T., et al. (2007). Cancer mortality in the United States by education level and race. Journal of the National Cancer Institute, 99, 1384-1394.

3. Al-Delaimy, W. K., Stampfer, M. J., Manson, J. E., \& Willett, W. C. (2008). Toenail nicotine levels as predictors of coronary heart disease among women. American Journal of Epidemiology, 167, 1342-1348.

4. Autier, P., Boffetta, P., Boniol, M., Boyle, P., Ferlay, J., Aurengo, A., et al. (2007). Attributable causes of cancer in France in the year 2000. Lyon: International Agency for Research on Cancer.

5. CDC Wonder. (2009). Mortality. Atlanta, Ga: Centers for Disease Control and Prevention. http://wonder.cdc.gov/mortSQL.html accessed 3/15/09

6. Davis, S., Malarcher, A., Thorne, S., Maurice, E., Trosclair, A., \& Mowery, P. (2009). State-specific prevalence and trends in adult cigarette smoking - United States, 1998-2007. MMWR Morbidity and Mortality Weekly Report, 58, 221-226.

7. Doll, R., \& Hill, A. B. (1950). Smoking and carcinoma of the lung; preliminary report. British Medical Journal, 2, 739-748.

8. Doll, R., \& Hill, A. B. (1954). The mortality of doctors in relation to their smoking habits; a preliminary report. British Medical Journal, 1, 1451-1455.

9. Doll, R., Gray, R., Hafner, B., \& Peto, R. (1980). Mortality in relation to smoking: 22 years' observations on female British doctors. British Medical Journal, 280, 967-971.

10. Doll, R., Peto, R., Boreham, J., \& Sutherland, I. (2004). Mortality in relation to smoking: 50 years' observations on male British doctors. BMJ, 328, 1519 .

11. Doll, R., Peto, R., Boreham, J., \& Sutherland, I. (2005). Mortality from cancer in relation to smoking: 50 years observations on British doctors. British Journal of Cancer, 92, 426-429.

12. Gruer, L., Hart, C., Gordon, D. S., \& Watt, G. (2009). Effect of tobacco smoking on survival of men and women by social position: A 28 year cohort study. BMJ, 338, b480.

13. Husten, C. G. (2009). How should we define light or intermittent smoking? Does it matter? Nicotine \& Tobacco Research, 11, 111-121.

14. Jemal, A., Ward, E., Anderson, R. N., Murray, T., \& Thun, M. J. (2008). Widening of socioeconomic inequalities in U.S. death rates, 1993-2001. PLoS ONE, 3, e2181.

15. Jha, P., Peto, R., Zatonski, W., Boreham, J., Jarvis, M. J., \& Lopez, A. D. (2006). Social inequalities in male mortality, and in male mortality from smoking: Indirect estimation from national death rates in England and Wales, Poland, and North America. Lancet, 368, 367-370.

16. Jousilahti, P., Vartiainen, E., Korhonen, H. J., Puska, P., \& Tuomilehto, J. (1999). Is the effect of smoking on the risk for coronary heart disease even stronger than was previously thought? Journal of Cardiovascular Risk, 6, 293-298.

17. Jousilahti, P., Salomaa, V., Kuulasmaa, K., Niemela, M., \& Vartiainen, E. (2005). Total and cause specific mortality among participants and non-participants of population based health surveys: A comprehensive follow up of 54372 Finnish men and women. Journal of Epidemiology and Community Health, 59, 310-315.

18. Kenfield, S. A., Stampfer, M. J., Rosner, B. A., \& Colditz, G. A. (2008). Smoking and smoking cessation in relation to mortality in women. JAMA, 299, 2037-2047.

19. Leistikow, B. (2004). Lung cancer rates as an index of tobacco smoke exposures: Validation against black male non-lung cancer death rates, 1969-2000. Preventive Medicine, 38, 511-515.

20. Leistikow, B. N., \& Tsodikov, A. (2005). Cancer death epidemics in United States Black males: Evaluating courses, causation, and cures. Preventive Medicine, 41, 380-385.
21. Leistikow, B. N., Chen, M., \& Tsodikov, A. (2006). Tobacco smoke overload and ethnic, state, gender, and temporal cancer mortality disparities in Asian-Americans. Preventive Medicine, 42, 430-434.

22. Leistikow, B. N., Kabir, Z., Connolly, G. N., Clancy, L., \& Alpert, H. R. (2008). Male tobacco smoke load and non-lung cancer mortality associations in Massachusetts. BMC Cancer, 8, 341.

23. Marshall, J. R., \& Hastrup, J. L. (1996). Mismeasurement and the resonance of strong confounders: Uncorrelated errors. American Journal of Epidemiology, 143, 1069-1078.

24. Marshall, J. R., Hastrup, J. L., \& Ross, J. S. (1999). Mismeasurement and the resonance of strong confounders: Correlated errors. American Journal of Epidemiology, 150, 88-96.

25. Peto, R., Lopez, A. D., Boreham, J., Thun, M., \& Heath, C. J. (1992). Mortality from tobacco in developed countries: Indirect estimation from national vital statistics [see comments]. Lancet, 339, 1268-1278.

26. Pope, C. A., 3rd, Ezzati, M., \& Dockery, D. W. (2009). Fineparticulate air pollution and life expectancy in the United States. The New England Journal of Medicine, 360, 376-386.

27. Samet, J. M., Norman, L. A., \& Wilbanks, C. (eds). (2004). The health consequences of smoking. U.S. Department of Health and Human Services, Centers for Disease Control and Prevention, National Center for Chronic Disease Prevention and Health Promotion, Office on Smoking and Health): Atlanta, Georgia.

28. Sarna, L., Bialous, S. A., Jun, H. J., Wewers, M. E., Cooley, M. E., \& Feskanich, D. (2008). Smoking trends in the Nurses' Health Study (1976-2003). Nursing Research, 57, 374-382.

29. SEER*Stat Database (2008) (National Cancer Institute, DCCPS, Surveillance Research Program, Cancer Statistics Branch. Underlying mortality data provided by NCHS (www.cdc.gov/nchs)).

30. Sesso, H. D., Gaziano, J. M., VanDenburgh, M., Hennekens, C. H., Glynn, R. J., \& Buring, J. E. (2002). Comparison of baseline characteristics and mortality experience of participants and nonparticipants in a randomized clinical trial: The Physicians' Health Study. Controlled Clinical Trials, 23, 686-702.

31. Steenland, K., Henley, J., \& Thun, M. (2002). All-cause and cause-specific death rates by educational status for two million people in two American Cancer Society cohorts, 1959-1996. American Journal of Epidemiology, 156, 11-21.

32. Taylor, D. H., Jr., Hasselblad, V., Henley, S. J., Thun, M. J., \& Sloan, F. A. (2002). Benefits of smoking cessation for longevity. American Journal of Public Health, 92, 990-996.

33. Thun, M. J., Day-Lally, C., Myers, D. G., Calle, E. E., Flanders, W. D., Zhu, B. P., et al. (1997). Trends in tobacco smoking and mortality from cigarette use in Cancer Prevention Studies I (1959-1965) and II (1982-1988). In L. Garfinkel, D. M. Burns \& J. M. Samet (Eds.), Changes in cigarette-related disease risks and their implication for prevention and control NIH publication no 97-4213, smoking and tobacco control monograph (pp. 305-522). Bethesda: National Cancer Institute, NIH, PHS, DHHS.

34. Thun, M. J., Hannan, L. M., Adams-Campbell, L. L., Boffetta, P., Buring, J. E., Feskanich, D., et al. (2008). Lung cancer occurrence in never-smokers: An analysis of 13 cohorts and 22 cancer registry studies. PLoS Medicine, 5, e185.

35. Van de Mheen, P. J. M., \& Gunning-Schepers, L. J. (1996). Differences between studies in reported relative risks associated with smoking: An overview. Public Health Reports, 111, 420 426. discussion 427.

36. Wacholder, S., Benichou, J., Heineman, E. F., Hartge, P., \& Hoover, R. N. (1994). Attributable risk: Advantages of a broad definition of exposure. American Journal of Epidemiology, 140, 303-309.

37. WHO Report on the Global Tobacco Epidemic. (2008). The MPOWER package. Geneva: World Health Organization. 